\title{
Neuroimaging Findings in Patients with COVID-19
}

\author{
DP. Nicholson, (D). Alshafai, and (D)T. Krings
}

O

\section{ABSTRACT}

SUMMARY: Little is known about the neurologic sequelae of coronavirus disease 2019 (COVID-19). We assessed neuroimaging findings in 4 patients positive for COVID-19. All had abnormal mental status, deranged coagulation parameters, and markedly elevated D-dimer levels. CT/MR imaging showed a common pattern of multifocal subcortical/cortical petechial-type hemorrhages, while SWI showed more extensive multifocal abnormalities. The appearances are consistent with a thrombotic microangiopathy and may be due to the heightened level of thrombosis in patients with COVID-19.

ABBREVIATIONS: COVID-19 = coronavirus disease 2019; ECMO = extracorporeal membrane oxygenation; SARS-CoV-2 = Severe Acute Respiratory Syndrome coronavirus 2

ittle has been published regarding neurologic outcomes in - patients with coronavirus disease 2019 (COVID-19), and little is known about its neurologic sequelae. However, there is increasing interest regarding the prothrombotic nature of the disease. ${ }^{1}$ We wished to highlight our recent experience with 4 patients with COVID-19 with neurologic symptoms and suggest how their findings may point to the underlying pathophysiology involved.

\section{MATERIALS AND METHODS}

We reviewed clinical and imaging findings in a series of patients with COVID-19 who underwent neurologic imaging while admitted to our center. This imaging was initiated as a result of a change in clinical neurologic status, and the 4 patients were part of a larger cohort of patients with COVID-19 admitted.

\section{Patient 1}

A 43-year-old man was admitted for extracorporeal membrane oxygenation (ECMO) following a failed trial of mechanical ventilation. On the fourth day, he developed acute pupil asymmetry.

Received April 30, 2020; accepted after revision May 12.

From the Division of Neuroradiology (P.N., T.K.), Joint Department of Medical Imaging, Toronto Western Hospital, University Health Network, University of Toronto, Toronto, Ontario, Canada; and Head and Neck Imaging (L.A.), Mount Sinai and University Health Network, University of Toronto, Toronto, Ontario, Canada. Please address correspondence to Patrick Nicholson, MB, Division of Neuroradiology, Toronto Western Hospital, 399 Bathurst St, Toronto, ON M5T 2S8, Canada; e-mail: patrick.nicholson@uhn.ca; @paddynicholson

- Indicates open access to non-subscribers at www.ajnr.org

Indicates article with supplemental on-line photo.

http://dx.doi.org/10.3174/ajnr.A6630
CT of the brain (Fig 1) showed a left frontal intraparenchymal hematoma with intraventricular hematoma and hydrocephalus. A fluid/fluid level was present within the hematoma, suggesting a possible underlying coagulopathy. There was a small amount of diffuse subarachnoid hemorrhage, petechial subcortical hemorrhage toward the vertex (arrow), and some hyperdense small cortical veins (arrowheads). No brain stem hemorrhage was present, but there was nearly complete effacement of the supratentorial CSF spaces. His white blood cell count was elevated at $15.2 \times$ $10^{9} / \mathrm{L}$, as was his D-dimer level $(>4400 \mu \mathrm{g} / \mathrm{L})$. His platelet count was in the normal range $\left(172 \times 10^{9} / \mathrm{L}\right)$, but his activated partial thromboplastin time was elevated (63.7 seconds) as was his prothrombin time (12.9 seconds) and serum ferritin level $(2186 \mu \mathrm{g} /$ L). He deteriorated and died shortly thereafter.

\section{Patient 2}

A 57-year-old man also underwent ECMO for respiratory failure. Following extubation, the patient demonstrated altered mental status and right-arm weakness. A CT scan (Fig 2) also showed multiple subcortical and subpial petechial hemorrhages. MR imaging, limited by motion artifacts (Fig 2B, $-C$ ), showed extensive petechial hemorrhages on SWI with some breakthrough small-volume parenchymal hematomas. There was also extensive parenchymal SWI abnormality, which appeared to correlate with a venular distribution and was predominantly in a subcortical pattern (as opposed, for example, to the deep gray matter SWI microhemorrhages, which can be seen in patients with hypertension). This subcortical SWI abnormality was not confined to 1 lobe of the brain but was rather more diffuse. The DWI sequences showed a few scattered multifocal cortical infarcts, but the 


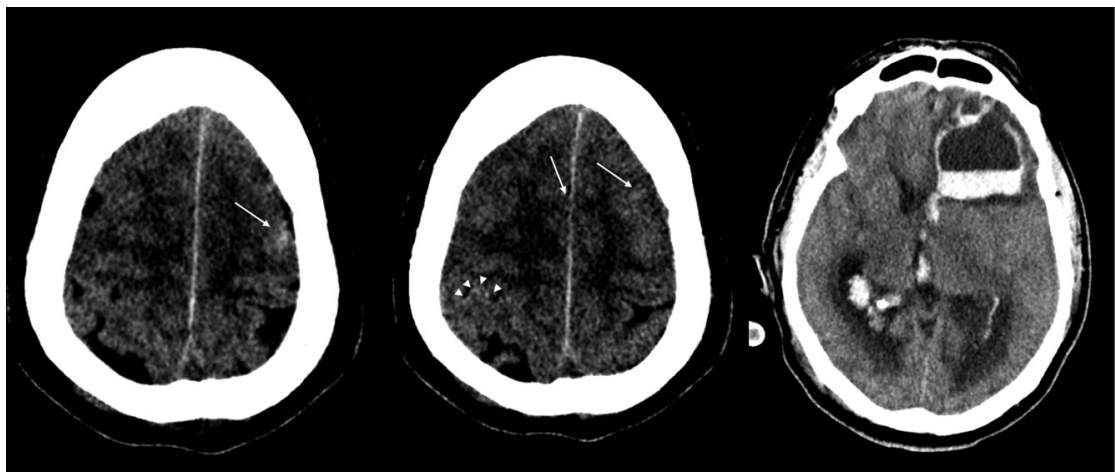

FIG 1. Patient 1. CT images show a left frontal intraparenchymal/intraventricular hematoma and hydrocephalus. A fluid-fluid level can be seen in the hematoma, and there is a small amount of diffuse subarachnoid hemorrhage, petechial subcortical hemorrhage toward the vertex (arrows), and some hyperdense small cortical veins (arrowheads).

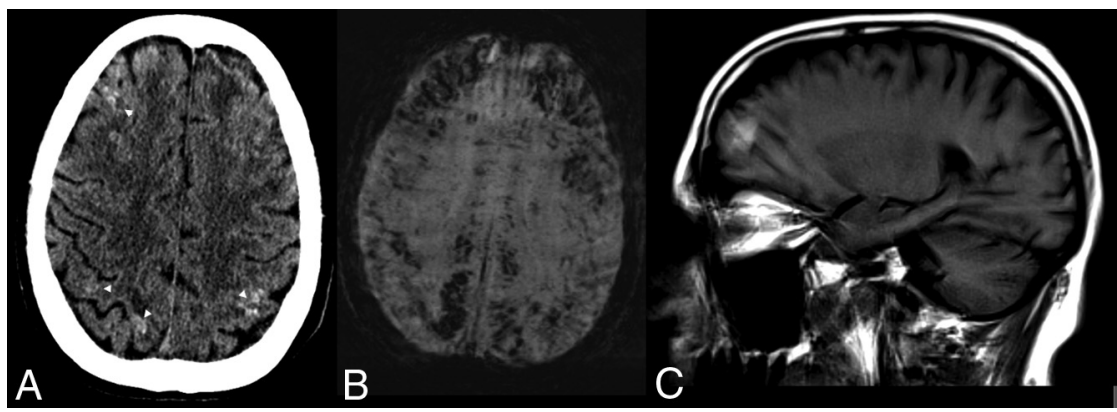

FIG 2. Patient 2. $A, C T$ scan shows multiple subcortical and subpial petechial hemorrhages. $B$ and $C$, MR imaging, limited by motion artifacts. $B$, Susceptibility-weighted axial image shows extensive SWI abnormality $C, \pi$ sagittal, noncontrast image shows some breakthrough macroscopic parenchymal hematomas.

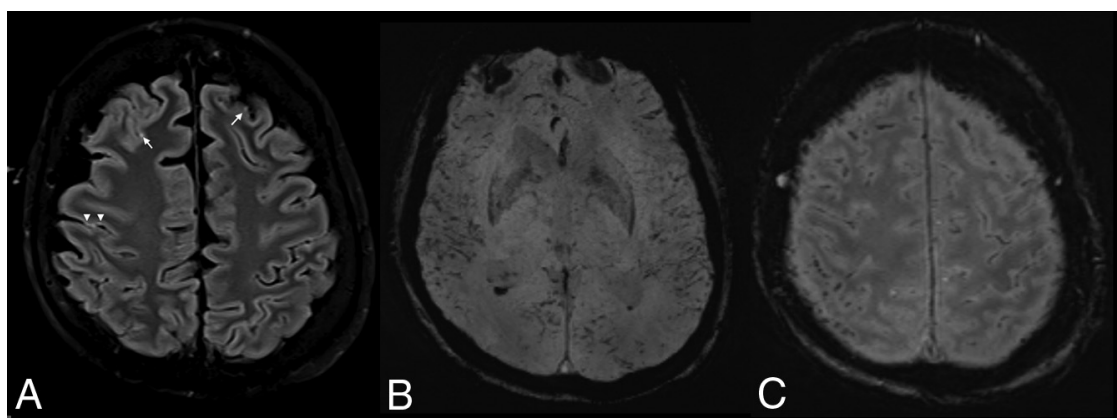

FIG 3. Patient $3 . A, T 2$ FLAIR imaging showing multifocal punctate juxtacortical T2 hyperintensities, compatible with small infarcts (arrows) and subtle more linear cortical T2 hyperintensity (arrowheads). B and C, SWI shows intraventricular blood. In addition, multifocal blooming is present in the subarachnoid and subpial spaces, as well as in multiple small cortical veins.

\section{Patient 3}

A 62-year-old man was ventilated for 7 days without ECMO and was slow to awake. Findings of a CT scan were unremarkable; MR imaging (Fig 3) showed trace intraventricular blood (with dependent "layering" in the ventricle) on SWI. In addition, multifocal "blooming" was present in the subarachnoid and subpial spaces, tracking along the cortex in a gyriform pattern. There was also extensive abnormal SWI signal tracking along small cortical veins in multiple territories and mild FLAIR hyperintensity along some cortical regions. High T2 signal was present in a subcortical distribution, along with callosal involvement. His white blood cell count was $14.3 \times 10^{9} / \mathrm{L}$, his $\mathrm{D}$ dimer level was $>4,400 \mu \mathrm{g} / \mathrm{L}$, and his platelet count was in the normal range $\left(211 \times 10^{9} / \mathrm{L}\right)$. His activated partial thromboplastin time was 65.7 seconds, and his prothrombin time was 15.2 seconds. His C-reactive protein level was also markedly elevated at $285 \mathrm{mg} / \mathrm{L}$.

\section{Patient 4}

A 57-year old woman was placed on ECMO for 12 days for respiratory failure secondary to COVID-19. On the first day following cessation of ECMO, she developed bilateral mydriasis. Her white blood cell count was $13.2 \times 10^{9} /$ $\mathrm{L}, \mathrm{D}$-dimer level was $>4400 \mu \mathrm{g} / \mathrm{L}$, and her platelet count was also in the normal range $\left(127 \times 10^{9} / \mathrm{L}\right)$. Activated partial thromboplastin time was 48.6 seconds, and prothrombin time, 11.6 seconds. Her C-reactive protein level was also elevated at $180 \mathrm{mg} / \mathrm{L}$. A CT of the brain was performed (On-line Figure), which showed a large rightsided parenchymal temporal hemorrhage with midline shift. In addition, there were multiple other areas of petechial-type cortical and subcortical areas of abnormal subcortical SWI signal showed no DWI abnormality. There was no significant T2/FLAIR edema, and no mass effect or sulcal effacement in these regions. His white blood cell count was $16.3 \times 10^{9} / \mathrm{L}$, and his D-dimer level exceeded $4400 \mu \mathrm{g} /$ L. His platelet count was also in the normal range $\left(174 \times 10^{9} / \mathrm{L}\right)$. His activated partial thromboplastin time was elevated at 63.7 seconds, as well as his prothrombin time (12.2 seconds) and his serum ferritin level $(4287 \mu \mathrm{g} / \mathrm{L})$. hemorrhages throughout both hemispheres. These appeared to be of mixed ages, and many had significant amounts of surrounding edema.

\section{DISCUSSION}

Little is known regarding effects of COVID-19 on the brain. Could it result in diffuse microvascular occlusion? Critical 
illness-associated microbleeds are a recognized phenomenon, ${ }^{2}$ albeit with an unclear etiology. It is possible that they are related to a hyperthrombotic/hypercoagulable state. Severe sepsis is known to be associated with a range of downstream effects of the inflammatory cascade that result from the body's attempts to fight infection, ${ }^{3,4}$ resulting in alterations in microvascular flow. In addition, a so-called "cytokine storm" has been implicated in COVID-19, ${ }^{5,6}$ and this phenomenon is known to have direct downstream effects on the vascular endothelium. ${ }^{7}$ The resultant thrombotic microangiopathy would then lead to end-organ dysfunction.

There is some evidence to support this hypothesis. Severe Acute Respiratory Syndrome coronavirus 2 (SARS-CoV-2) enters cells via the angiotensin-converting enzyme 2 receptor, which is widely expressed in both vascular smooth muscle and endothelin. ${ }^{8}$ Indeed 1 group has recently documented endothelial COVID-19 cell infection with endothiliitis and vasculitis in multiple organs. ${ }^{9}$ Others have shown a thromboembolism rate of $30 \%$ in severely ill patients with COVID-19, ${ }^{10}$ which is remarkably high considering that a multicenter study of $>7400$ critical care patients in 2015 showed thromboembolism rates of $7.7 \%{ }^{11}$ This elevated rate of thromboembolic complications has led some teams to speculate that it could also be due to an obstructive pulmonary microvascular thrombosis. ${ }^{12}$ Another group recently published skin and lung pathologic samples in patients with severe COVID-19 and skin rash. Their patients had extensive microvascular thrombosis, which appeared to be mediated by complement deposition and an associated procoagulopathy. ${ }^{13}$ Recent evidence has shown that SARS-CoV-2 can directly infect and propagate within vascular endothelial cells. ${ }^{14}$ Finally, risk factors that are known to be associated with endothelial dysfunction (such as hypertension, diabetes, and obesity) ${ }^{15}$ are related to worse outcomes in patients with COVID-19. ${ }^{16}$

Our imaging would be compatible with this theory, with multifocal abnormal SWI signal suggestive of a possible diffuse thrombotic microangiopathy, potentially with both arterial and venous components. Indeed, the multifocal cortical infarcts point toward a potential arterial microvascular thrombosis, while the hyperdense veins we saw on some studies could be indicative of sluggish venous flow. Unchecked diffuse thrombosis could then lead to blood-brain barrier breakdown, multifocal petechial bleeding, and eventual massive hemorrhage. Some patients could also then experience venous infarcts, which could explain the pattern seen in patient 1 , for example.

This study has some caveats, of course. As stated earlier, cerebral microbleeds are a recognized phenomenon associated with critical care/sepsis (though the underlying mechanism may be similar to what we have stated). Some of the imaging findings we are seeing could be attributed to ECMO. For example, 1 series showed that up to $50 \%$ of patients having undergone ECMO experienced neurologic events, ${ }^{17}$ and other groups have shown similar imaging patterns. ${ }^{18}$ However, not all our patients were on ECMO despite similar imaging findings, so we believe it is more likely related to COVID-19 than to ECMO alone. Finally, we do not suggest that our limited single-center data are determinative, but rather hypothesisgenerating.

\section{CONCLUSIONS}

We present a series of patients in keeping with the growing body of evidence regarding the prothrombic nature of patients with COVID-19. More data are needed regarding neuroimaging findings in these patients, but in the meantime, we strongly encourage clinicians to be aware of the possibility of a diffuse microvascular thrombotic-type picture and to have a low threshold for brain MR imaging in patients with COVID-19 with altered mental status.

Disclosures: Laila Alshafai-UNRELATED: Employment: University Health Network and Mount Sinai Hospital. Timo Krings-UNRELATED: Consultancy: Stryker, Medtronic, Penumbra; Royalties: Thieme; Stock/Stock Options: Marblehead.

\section{REFERENCES}

1. Oudkerk M, Büller HR, Kuijpers D, et al. Diagnosis, prevention, and treatment of thromboembolic complications in COVID-19: report of the National Institute for Public Health of the Netherlands. Radiology 2020 Apr 23. [Epub ahead of print] CrossRef Medline

2. Fanou EM, Coutinho JM, Shannon P, et al. Critical illness-associated cerebral microbleeds. Stroke 2017;48:1085-87 CrossRef Medline

3. Iba T, Levi M, Levy JH. Sepsis-induced coagulopathy and disseminated intravascular coagulation. Semin Thromb Hemost 2020;46:8995 CrossRef Medline

4. Ding R, Wang Z, Lin Y, et al. Comparison of a new criteria for sepsis-induced coagulopathy and International Society on Thrombosis and Haemostasis disseminated intravascular coagulation score in critically ill patients with sepsis 3.0: a retrospective study. Blood Coagul Fibrinolysis 2018;29:551-58 CrossRef Medline

5. Ye Q, Wang B, Mao J. The pathogenesis and treatment of the 'Cytokine Storm' in COVID-19. J Infect 2020;80:607-13 CrossRef Medline

6. Mehta P, McAuley DF, Brown M, et al. COVID-19: consider cytokine storm syndromes and immunosuppression. Lancet 2020;395:103334 CrossRef Medline

7. Teijaro JR, Walsh KB, Cahalan S, et al. Endothelial cells are central orchestrators of cytokine amplification during influenza virus infection. Cell 2011;146:980-91 CrossRef Medline

8. Ferrario CM, Jessup J, Chappell MC, et al. Effect of angiotensin-converting enzyme inhibition and angiotensin II receptor blockers on cardiac angiotensin-converting enzyme 2. Circulation 2005;111:260510 CrossRef Medline

9. Varga Z, Flammer AJ, Steiger P, et al. Endothelial cell infection and endotheliitis in COVID-19. Lancet 2020;395:1417-18 CrossRef Medline

10. Leonard-Lorant I, Delabranche X, Severac F, et al. Acute pulmonary embolism in COVID-19 patients on CT angiography and relationship to D-dimer levels. Radiology 2020 Apr 23. [Epub ahead of print] CrossRef Medline

11. Lim W, Meade M, Lauzier F, et al; PROphylaxis for ThromboEmbolism in Critical Care Trial Investigators. Failure of anticoagulant thromboprophylaxis: risk factors in medical-surgical critically ill patients. Crit Care Medicine 2015;43:401-10 CrossRef Medline

12. Ciceri F, Beretta L, Scandroglio AM, et al. Microvascular COVID19 lung vessels obstructive thromboinflammatory syndrome (MicroCLOTS): an atypical acute respiratory distress syndrome working hypothesis. Crit Care Resusc 2020 Apr 15. [Epub ahead of print] Medline

13. Magro C, Mulvey JJ, Berlin D, et al. Complement associated microvascular injury and thrombosis in the pathogenesis of severe COVID-19 infection: a report of five cases. Transl Res 2020 Apr 15. [Epub ahead of print] CrossRef Medline

14. Monteil V, Kwon H, Prado P, et al. Inhibition of SARS-CoV-2 infections in engineered human tissues using clinical-grade soluble human ACE2. Cell 2020;181:905-13.e7 CrossRef Medline 
15. Deanfield JE, Halcox JP, Rabelink TJ. Endothelial function and dysfunction. Circulation 2007;115:1285-95 CrossRef Medline

16. Richardson S, Hirsch JS, Narasimhan M, et al. Presenting characteristics, comorbidities, and outcomes among 5700 patients hospitalized with COVID-19 in the New York City area. JAMA 2020 Apr 22. [Epub ahead of print] CrossRef Medline
17. Mateen FJ, Muralidharan R, Shinohara RT, et al. Neurological injury in adults treated with extracorporeal membrane oxygenation. Arch Neurol 2011;68:1543-49 CrossRef Medline

18. Guennec LL, Bertrand A, Laurent C, et al. Diffuse cerebral microbleeds after extracorporeal membrane oxygenation support. Am J Respir Crit Care Med 2015;191:594-96 CrossRef Medline 